\title{
A Cross National Study Of The Effect Of Group Orientation Culture On Inter-Organizational Relationship
}

\author{
Sungmin Ryu, Sungkyunkwan University, South Korea
}

\begin{abstract}
Exchange parties from diverse cultures need to maintain good quality relationships with their partners. Based on the existing literature, however, it remains unclear as to how culture affects the quality of relationships. The principal contention of this study is that an exchange party's adoption of a group orientation culture will improve relationship quality. The results of a survey research effort fielded among manufacturing companies in Korea and the USA demonstrate that group orientation culture positively influences the continuation of interfirm relationships and commitments. Specifically, manufacturers that adopt group orientation cultures can expect continued relationships with their suppliers, and they are also more likely to want to maintain these relationships, due to the presence of positive emotional bonds with their partners.
\end{abstract}

\section{INTRODUCTION}

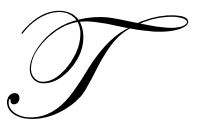

he subject of relationship marketing has been the focus of a substantial amount of attention in the business-to-business marketing literature. The maintenance of a mutually beneficial relationship with exchange partners has been recognized as a crucial factor for achieving better exchange performance (Manna 2008; Noordewier, John, \& Nevin 1990). Thus, scholars have long studied the factors that influence relationship quality (Kumar, Scheer, \& Steenkamp 1995; Anderson \& Weitz 1992).

Although several factors affecting relationship quality have been studied, the majority of business-tobusiness studies are conducted on the basis of an individualistic perspective view of Western culture (Lusch \& Brown 1996; Kumar, Scheer, \& Steenkamp 1995). Thus, few studies have been conducted thus far regarding the quality of interfirm relationships from the group oriented perspective associated with Eastern cultures. For instance, the influence of culture (i.e., group orientation culture) on interfirm relationship quality has been only rarely addressed in the relevant literature (Robicheaux \& Coleman 1994). Thus, it is necessary to explore the manner in which exchange parties in Eastern culture have been able to improve the quality of their relationships with their partners.

In the area of cross-cultural study, innumerable studies have been conducted regarding which cultures establish favorable environments for developing quality relationships within the organization (Gooden \& Preziosi 2004; Williams, Han, \& Qualls 1988). For example, group orientation cultures contribute to low conflict and high cooperation between members of an organization, due to the fact that group orientation cultures force their members to harmonize with other members.

The principal objective of this study was to help clarify the conditions under which relational quality can be improved. In particular, the existing literature remains unclear with regard to the manner in which culture affects relationship quality. Our contention is that an exchange party that adopts a group orientation culture will enjoy an improvement in relationship quality. Exploring the effects of group orientation cultures will help us to obtain knowledge that should prove helpful in gaining an understanding of relationship quality between and among exchange parties. 
In the following section, the theoretical framework of cultural dimensions and relationship quality will be presented. The research hypotheses are provided in the subsequent section. The methodology and analysis of results are provided in the section following the hypotheses section.

\section{THEORY AND HYPOTHESES}

\section{Group Orientation Culture}

Among the several cultural dimensions developed by Hofstede (1991), group orientation is addressed in this study. Group orientation has been shown to be a strong theoretical background and has garnered corroborative empirical results (Triandis 1995). The other dimensions, including power distance, masculinity, and uncertainty avoidance, were derived via exploratory factor analysis, in the absence of any theoretical background. Thus, these dimensions are considered inappropriate for this research.

Collective culture is defined as the extent to which a society consists of members who see themselves as a part of a group (Triandis 1995). Collectivists therefore emphasize the association of a group member with the relevant group. Collectivists perceive an obligation toward the well-being of the group that trumps their personal desires. In cases in which a conflict exists between individual interests and the group interest, collectivists tend to afford priority to the group interest, whereas individualists afford priority to self-interest (Triandis 1995). Therefore, in collectivist cultures, collectivism connotes concern for others, unselfishness, and placing the interest of the group above self-interest (Wagner 1995; Kim et al. 1994).

The group is very important for collectivists, in that it is the means by which its members identify themselves. Collectivists include group membership in their self-identification, whereas individualists define themselves as autonomous entities, independent of groups (Wagner 1995). As the group so profoundly informs collectivists' identities, group members often perceive themselves as sharing a 'common fate' (Triandis, McCusker, \& Hui 1990). Thus, this cohesive characteristic of collective culture toward a group engenders a more positive attitude toward other group members. Collectivists tend to compare the group to which they belong to with other groups with which they are not affiliated (Brewer and Kramer 1985). Via this comparison, they strengthen their positive self-image (Earley 1993).

Collectivists are quite sensitive to the ingroup-outgroup boundary (Triandis 1989). The ingroup is a group of individuals with whom the collectivist is willing to cooperate, and the outgroup is a group of people with whom the collectivist shares no common interests (Triandis 1995). The members of an ingroup view their long-term welfare as a function of the success of the group (Hofstede 1980). Therefore, the behavior of collectivists toward ingroup members tends to differ from their behavior toward outgroup members (Triandis, McCusker, \& Hui 1990). Collectivists tend to have more intimate relationships with members of their ingroup (Triandis 1995), and generally have more superficial relationships with outgroup members (Kim et al. 1994).

Collectivists perceive ingroup member's trustworthiness positively and maintain cooperative relationships with other ingroup members (Brewer \& Kramer 1985). Although individualists also certainly have a notion of ingroup and outgroup, they do not evidence significantly different behavior toward ingroup and outgroup members, as do collectivists (Triandis, McCusker \& Hui 1990). Earley (1993) previously reported that collectivists' performance tended to be higher when working in an ingroup than in an outgroup, whereas the performances of individualists tend to be higher when working alone than in either an ingroup or an outgroup.

Collectivists place the bulk of their emphasis on harmonious relationships with other ingroup members at the expense of task accomplishment, whereas individualists tend to pay less attention to relationships, and are more task-oriented (Kim et al. 1994). Thus, collectivists attempt to prevent and avoid conflict with other ingroup members and stress cooperation with them. Collectivists, then, can be said to enjoy favorable conditions for the development of cooperative relationships with other ingroup members (Triandis 1995). 
In collectivist cultures, the fact that a party begins to do business with its new partner means that the party accepts the new partner into its ingroup (Griffith, Hu \& Ryans 2000; Shankarmahesh, Ford \& LaTour 2003). Thus, unless a party treats its partner as an ingroup member, the party will tend against engaging fully in business with the partner.

\section{Relationship Quality}

The maintenance of quality relationships with exchange partners is one of the principal factors in creating superior performance. In the relationship between parts suppliers and manufacturers, a supplier's provision of parts at a low price positively affects the manufacturer's buying performance. A manufacturer should therefore strive to maintain a good relationship with its supplier. Relationship quality relies on the level of trust, conflict, the intention to continue the relationship, and commitment (Kumar, Scheer \& Steenkamp 1995).

Expectation of continuity refers to the tendency of exchange parties to gain long-term benefits via a relationship with their partners (Ganesan 1994). The relationships in a group orientation culture are likely to be stable (Triandis et al. 1988), as people in group orientation cultures tend to tolerate the foibles of their partners, keeping their focus on the long-term survival of the relationship (Kale 1986). In a volatile environment, exchange parties tend to behave opportunistically in order to take advantage of unclear situations (Williamson 1985). However, a stable relationship faces few turbulent factors which negatively influence the relationship. Thus, exchange parties in a stable relationship have a better chance of understanding each other, which results in an improved relationship. Improved relationship quality thus allows exchange parties to anticipate a continuing relationship with their partners. On that basis, the first hypothesis is as follows:

H1: The more an exchange party adopts group orientation culture, the more the party anticipates a continuing relationship with its partner.

Conflict refers to mutual goal interference, in which one party perceives the other to be blocking its goal attainment and reacts accordingly to block the other's goal attainment (Stern, Sternthal \& Craig, 1973). In group orientation cultures, confrontation with other members is considered to be highly undesirable (Triandis et al. 1988), and harmony with group members is emphasized (Fijneman, Willemsen \& Poortinga 1996; Triandis, McCusker \& Hui, 1990). As conflicts between members could cause a disruption of harmony, group orientation cultures force exchange parties to reduce the level of conflict in their relationships with their partners. Members in a group orientation culture are generally likely to compromise (Kirkbridge, Tang \& Westwood, 1991). These arguments form the underpinning for the second hypothesis, which is:

H2: The more an exchange party adopts group orientation culture, the less conflict the party generates with its partner.

$\underline{\text { Trust }}$ involves the willingness to rely on an exchange partner in which a party has confidence (Moorman, Zaltman \& Deshpande 1992), and the expectation that the partner will perform as expected (Anderson \& Weitz 1989). As trust involves an exchange party's belief that its partner will keep its promises, there exists the possibility that the partner will not perform as promised. Therefore, trust intrinsically involves vulnerability on the part of the trustor, due to the self-interest-seeking behavior of the trustee (Chiles \& McMackin 1996).

Group orientation cultures place priority on collective interest over individual interest (Triandis 1995). In group-oriented cultures, too much assertion of self-interest will be perceived as a challenge to the relationship between members (Chen, Chen \& Meindl 1998). This is one of the reasons that Japan, a group-oriented culture, has developed collective sanctioning mechanisms to protect the benefits of its business community (Hagen \& Choe 1998). With the help of collective sanctions, exchange parties can develop trust among themselves (Hagen \& Choe 1998). Thus, exchange parties that adopt a group orientation culture are compelled not to betray their partners, which causes the exchange parties not to worry about the vulnerability associated with trust in their partners. On the basis of that assertion, the third hypothesis is as follows: 
H3: The more an exchange party adopts group orientation culture, the greater trust the party cultivates with its partner.

Commitment refers to the desire to continue a relationship due to a positive emotional bond with the partner (Kumar, Scheer \& Steenkamp 1995). Members of a group-oriented culture tend to feel intimately related with other members (Triandis, McCusker \& Hui 1990). As this intimate relationship between exchange parties affords them a chance to understand each other, this intimacy becomes the basis for developing shared values between exchange parties. Thus, communal sharing and emotional closeness with exchange partners are principal characteristics of ingroup relationships in group orientation cultures (Chen, Chen \& Meindl 1998). As common values provide the members of groups with an emotional bond, group orientation cultures help their members to nurture commitments between them. Thus, the fourth hypothesis is as follows:

H4: The more an exchange party adopts a group orientation culture, the greater the commitment the party will generate in the relationship with its exchange parties.

\section{METHOD}

\section{Context}

In an effort to test the hypotheses regarding the influence of culture on the relationship between manufacturers and their suppliers, manufacturers in Korea and U.S.A. were selected. Korea and U.S.A. were selected for two key reasons. First, Korea is among the most group-oriented countries, and the U.S.A. is one of the least group-oriented countries (Hofstede 1991). Second, although Korea has been developing rapidly for the past 30 years, research regarding interfirm relationships in Korea has been only rarely attempted. Thus, the extension of our knowledge of interfirm relationships in Korea appears a worthwhile objective. The data utilized to assess the hypotheses in this study were collected via a mail survey.

Manufacturers were selected via a systematic random sampling of 465 firms from the mailing list of the Korean Manufacturer's Association in Korea and 585 U.S. manufacturing firms from the Dunn and Bradstreet directory (SIC 31 to 39). The sample of respondents was drawn from a variety of industries to enhance the generalizability of the results, by minimizing the effects of industry-specific characteristics.

The heads of the purchasing departments of the manufacturing companies were selected as key informants. Purchasing managers are responsible for securing materials from suppliers, and thus they can be expected to be knowledgeable about resources dealt with and also those pertaining to the relationship with suppliers (Hutt \& Speh 2000).

On the basis of telephone contacts, purchasing managers were identified. Each purchasing manager was subsequently mailed a questionnaire and asked to complete it. After callbacks and a second mailing, 101 (Korea) and 120 (USA) questionnaires were collected. Response rates were approximately $22 \%$ and $21 \%$, respectively.

Non-response bias was evaluated by a comparison of early respondents with late respondents. No significant differences were detected on variables including the number of employees, percentage of purchasing volume, and years of experience, which suggests that non-response bias may not exist.

\section{Measurement}

Group Orientation Culture: The items associated with collectivism involve principally the individual's emotional attachment to the organizations or families to which they belong. The items were as follows: being born into an extended family, prevalence of 'we' consciousness, the family as a base of identity, emotional dependence on the organization, taking care of oneself only, and the acceptance of a organization's invasion of individual life. The first three items were utilized by Hofstede (1980), and the rest of the items were developed by the authors. 
The expectation of continuity: The items associated with the expectation of interaction are representative of the tendency of exchange parties to continue relationships with their exchange partners. The expectation of continuity consists of three items: the expectation of the exchange relationship to continue for a long time, automatic renewal of the exchange relationship, and the long-term alliance of the exchange relationship. The first two items were adopted from the work of Kumar, Scheer, and Steenkamp (1995), and the final item was utilized by Lusch and Brown (1996).

Conflict: Conflict is assessed in accordance with three items. The scale assesses the extent of disagreement between exchange parties. The items were the existence of conflict, major disagreement on key issues, and arguments on key decisions. The first two items were adopted from the work of Kumar, Scheer \& Steenkamp (1995), and the final item was constructed by the authors.

Trust: Three dimensions of trust--honesty, credibility, and benevolence--were assessed in accordance with two, three, and two items respectively. The items for honesty were confidence in partner's trustworthiness and the extent of the partner's honesty. The scale for credibility addresses the partner's commitment to its promises, keeping the promises of the partner, and counting on the partner's sincerity. The items for benevolence were the exchange partner's concern regarding the business success and welfare of the respondent's company. These items were adapted from the work of Doney \& Cannon (1997).

Commitment: Commitment involves internalizing the value of continuing an exchange relationship with one's partner. The scale for affective commitment consists of three emotional reasons for continuing a relationship with a partner: association with the partner, enjoying the relationship, and positive feelings toward the partner. These items were adopted from the work of Kumar, Scheer, and Steenkamp (1995).

Table 1

Reliability for Dependent Variables

\begin{tabular}{|c|c|c|c|}
\hline Scales & Alpha & $\begin{array}{l}\text { Standardized } \\
\text { Loading }\end{array}$ & t-value \\
\hline Expectation of interaction (CONTI) & .7714 & & \\
\hline CONTI1: continuing the relationship for a long time & & .77 & 8.22 \\
\hline CONTI2: automatic renewal of exchange relationship & & .86 & 9.40 \\
\hline CONTI3: long-term alliance of the exchange relationship & & .58 & 5.87 \\
\hline Trust (TRUST) & .7010 & & \\
\hline TRUST1: confidence in partner's trustworthy & & .76 & 8.18 \\
\hline TRUST2: the extent of partner's honesty & & .32 & 3.05 \\
\hline TRUST3: partner's commitment to its promise & & .46 & 4.48 \\
\hline TRUST4: keeping promise of partner & & .58 & 5.94 \\
\hline TRUST5: counting on partner's sincereness & & 62 & 6.28 \\
\hline TRUST6: partner's concern about respondent's firm & & .54 & 5.30 \\
\hline Conflict (CONFLICT) & .7145 & & \\
\hline CONFLICT1: the existence of conflict & & .92 & 10.72 \\
\hline CONFLICT2: major disagreement on key issues & & .63 & 6.54 \\
\hline CONFLICT3: the argument on key decisions & & .71 & 7.61 \\
\hline Commitment (COMMIT) & .7183 & & \\
\hline COMMIT1: being association with the partner & & .64 & 5.97 \\
\hline COMMIT2: enjoying the relationship & & .59 & 5.54 \\
\hline COMMIT3: positive feeling toward the partner & & .80 & 7.43 \\
\hline Group Orientation Culture (GROUP) & .7005 & & \\
\hline GROUP1: born into extended families & & .49 & 4.09 \\
\hline GROUP2: emotional dependence on organization & & .51 & 4.16 \\
\hline GROUP3: the basis of identity on family & & .86 & 5.74 \\
\hline
\end{tabular}

Fit statistics for confirmatory factor analysis: $\chi^{2}=116.50 \mathrm{df}=121(\mathrm{p}=.59)$, Goodness-of-Fit Index (GFI) =.89 Non-Normed Fit Index $(\mathrm{NNFI})=1.00$, Comparative Fit Index $(\mathrm{CFI})=1.00$. 


\section{Construct Validity}

Each latent variable that was measured with multiple items was subjected to the scale purification procedure. On the basis of the item-to-total correlations, the ill-fitted items were excluded. Among the five items for group-oriented cultures, group consciousness (GROUP1), taking care of oneself only (GROUP2), and invasion of private life by organization (GROUP3) were excluded from the model. These items diminish the overall reliability and show very little loading to the assigned factor. After deleting these items, an acceptable fit of factor model was acquired. Items converged on their assigned factors and loaded significantly.

Following the scale purification process, a measurement model with acceptable fit indices was identified. All of the composite reliabilities for five $($ CONTI $=.7714$, TRUST $=.7010$, CONFLICT $=.7145$, COMMIT $=$ .7183 , GROUP $=.7005)$ exceed the standard of .70 (Churchil 1979). Confirmatory factor analysis indicated that five latent variables--Expectation of interaction (CONTI), Trust (TRUST), Conflict (CONFLICT), Commitment (COMMIT), and Group Orientation Culture (GROUP)-- adequately fit the data $\left(\chi^{2}=116.50 \mathrm{df}=121(\mathrm{p}=.59)\right.$, GFI $=.89 \mathrm{NNFI}=1.00, \mathrm{CFI}=1.00)$. All the factor loadings were highly significant $(\mathrm{p}<.01)$, showing evidence of convergent validity and the unidimensionality of the measures (Anderson and Gerbing 1988).

The discriminant validity of all 5 of the latent variables was assessed via $\chi^{2}$ Difference Tests: all the constructs in pairs (10 tests altogether) were tested in cases in which the restricted model (in which the correlation was fixed as one) was significantly worse than the freely estimated model (in which the correlated was estimated freely). All the $\chi^{2}$ differences were highly significant, thus corroborating discriminant validity (Anderson and Gerbing 1988). For example, the comparison of TRUST with CONFLICT yielded a $\square^{2}(1)=22.43$ ( $\left.p<.01\right)$ for the data, thereby suggesting that these two constructs are distinct.

Table 2

Correlation Matrix

\begin{tabular}{|l|ccccc|}
\hline & 1 & 2 & 3 & 4 & 5 \\
\hline 1. GROUP & 1.000 & & & & \\
2. CONTI & .327 & 1.000 & & & \\
3. TRUST & .095 & .428 & 1.000 & 1.000 & \\
4. CONFLICT & -.153 & -.241 & -.526 & -.185 & 1.000 \\
5. COMMIT & .221 & .044 & .216 & & 5.02 \\
& & & & & \\
Mean & 4.55 & 5.23 & 4.92 & 3.04 & .95 \\
\hline SD & .82 & .78 & 1.08 & 1.03 & \\
\hline
\end{tabular}

\section{ANALYSIS AND RESULTS}

The proposed structural model was specified from the hypothesized relationships. The model is provided in Table 3. Wong et al. (1999) demonstrated that trust is negatively related with conflict. As the notion of conflict involves the interference of one party with the goal of its partner, a party in conflict with its partner may not possess confidence in its partner. Thus, the party does not expect that the partner will perform as anticipated. In dealing with highly correlated endogenous variables, several researchers (e.g., Bello \& Gilliland 1997; Jaworski \& MacInnis 1989) have correlated the structural error of these variables. We operated in accordance with this practice and assessed the model by correlating the structural errors associated with trust and conflict. 
Table 3

LISREL Analysis for hypothesis

\begin{tabular}{|lcccc|}
\hline Description & \multicolumn{2}{c}{ Hypotheses } & \multicolumn{2}{c|}{ Hypothesized Model } \\
\hline & Number & Sign & Coefficient & t-value \\
\hline GROUP $\rightarrow$ CONTI & H1 & + & .26 & 2.55 \\
GROUP $\rightarrow$ CONFLICT & H2 & + & -.03 & -0.33 \\
GROUP $\rightarrow$ TRUST & H3 & + & .02 & 0.19 \\
GROUP $\rightarrow$ COMMIT & H4 & + & .19 & 1.76 \\
\hline
\end{tabular}

Fit statistics for confirmatory factor analysis: $\chi^{2}=16.29, \mathrm{df}=7(\mathrm{p}=.12)$,

Goodness-of-Fit Index $(\mathrm{GFI})=.90$ Non-Normed Fit Index $(N N F I)=1.00$,

Comparative Fit Index $(\mathrm{CFI})=.90$ Root Mean Square Residual $(\mathrm{RMR})=.08$

\section{Tests Of Hypotheses}

The theoretical model adequately fits the data $\left(\chi^{2}=16.29, \mathrm{df}=7, \mathrm{p}=.12\right.$, GFI $\left.=.96, \mathrm{CFI}=.90, \mathrm{RMR}=.08\right)$. Some of the hypothesized paths (GROUP $\rightarrow$ CONTI, GROUP $\rightarrow$ COMMIT) were significant, whereas some paths (GROUP $\rightarrow$ TRUST, GROUP $\rightarrow$ CONFLICT) were not significant. This result indicates group orientation culture strongly influences the relationship between exchange parties. In particular, group orientation culture increases expectations of continuity and commitment.

The result in Table 4 shows that $\mathrm{H} 1$ and $\mathrm{H} 4$ were supported. The findings for $\mathrm{H} 1\left(\gamma_{12}=.26, \mathrm{t}=2.55\right)$ suggest that as an exchange party adopts its national culture of group orientation, the party is likely to continue a relationship with its partner. Findings for $\mathrm{H} 4\left(\gamma_{42}=.19, \mathrm{t}=1.76, \mathrm{p} \leq .10\right)$ support this hypothesis. As expected, the exchange party's adoption of group-oriented culture is likely to result in the development of commitment with partners.

However, two hypotheses regarding the influence of group orientation culture on trust and conflict are not supported. In H2, it is hypothesized that the more an exchange party adopts its national culture of collectivism, the lower levels of conflict it can expect with its partner. As conflict prevents group members from cooperating with other members (Wagner 1995), an exchange party in a group-oriented culture is likely to attempt to reduce conflict with its exchange partner. However, the findings for $\mathrm{H} 2\left(\gamma_{32}=-.03, \mathrm{t}=0.33\right)$ do not support this hypothesis.

This result can be explained by two reasons. One of these might be that conflict performs a positive function in relationships between parties as long as the parties employ the conflict as a chance to improve relationship quality (Gupta, Ashok \& Wilemon 1986). Thus, the interaction between exchange parties in an effort to address the conflict may contribute to the maintenance of harmony between them. Thus, the emphasis on harmony (Triandis, McCusker $\&$ Hui 1990) by group orientation cultures does not actively push group orientations to reduce conflict between them. The opposite explanation may also apply. As the stress of maintaining harmony in group orientation cultures is enormous (Fijneman, Willemsen \& Poortinga 1996), exchange parties in the group orientation culture may feel pressure not to reveal any indication of conflict to their partners. Therefore, they may not have a chance to solve the conflict, which results in a high level of conflict between them.

The findings for $\mathrm{H} 3\left(\gamma_{22}=.02, \mathrm{t}=0.19\right)$ show that although the theoretical explanation for the influence of group orientation culture on trust is quite profound, an exchange party's adoption of group orientation culture can fail to influence the cultivation of trust with exchange partners. As group orientation cultures compel their members to restrain assertions of self-interest (Chen, Chen \& Meindl 1998), exchange parties in a group orientation culture may not worry overly about the vulnerability implicit in trusting their partners. However, the results indicate that group orientation culture does not contribute to the development of trust. 


\section{DISCUSSION}

\section{Limitation}

Only one dimension of culture in were investigated in this study; namely group orientation culture. The study did not include other cultural dimensions, such as power distance masculinity, and uncertainty avoidance (Hofstede 1991). These other cultural dimensions may also influence the relationship between exchange parties. Therefore, the results obtained from LTO and collectivism are limited.

In accordance with the data obtained from the manufacturers, the results are not reflective of the dyadic relationship. It may prove interesting to determine how the difference between exchange parties in terms of accepting group orientation culture will influence relationships. Although a manufacturer's tendency to accept group orientation culture may reflect the manufacturer's interactions with its partners, it is also possible that exchange parties may differ in regard to their adopted cultures. It will be very interesting to assess the manner in which such differences affect relationships.

\section{Future Research Direction}

Culture functions as a control mechanism which directs the behavior of its members (Geertz 1965). Thus, culture provides its members with rules and instructions that guide them as to how to behave in a given situation. Without such rules and regulations, exchange parties face difficulties in conducting transactions with their partners. For instance, US manufacturers have been struggling with their efforts to establish JIT systems, due to low part quality and poor delivery time performance (Kumon et al. 1994). It is, therefore, interesting to see how a culture influences exchange parties to adopt control mechanisms. The control mechanisms relied upon by East Asian exchange parties may differ from those of Western exchange parties.

It is interesting to study how an exchange party in a highly group-oriented culture interacts with its partner in a low-level group orientation culture. Although Bellow and Gilliland (1997) studied the relationship between exchange parties in a cross-national setting, they did not adopt a cultural approach. How does a party in a grouporiented culture interact with its partner in an individual-oriented culture? Does a party in a group-oriented culture consider its partner from a low-level group-oriented culture an ingroup member or an outgroup member? Depending on the decision, the relationship may be strongly influenced. If a party treats its foreign partner as an outsider, it may have to utilize different control mechanisms than it does with ingroup members.

\section{Managerial Implications And Recommendations}

Trust reduces the need to monitor exchange partners (Ouchi 1979), which effectively lowers transaction costs (Dyer \& Chu 2003). Trust provides manufacturers with confidence in their supplier's performance, including on-time delivery and the expected level of product quality. Thus, manufacturers do not need to spend a great deal of money to monitor their suppliers. Exchange parties with high group orientation cultures in East-Asian countries thus enjoy the advantages of low transaction costs, which translates directly to higher profits.

According to these findings, group orientation culture positively influences the development of commitment to a relationship between partners. Exchange parties with high levels of commitment to the relationship tend to develop cooperative relationships (Morgan \& Hunt 1994). The close emotional relationships between them provide them with a chance to understand each other. Thus, they can maintain a cooperative relationship. Exchange parties operating in a group orientation culture should thus pay attention to their level of emotional closeness with their partners. Otherwise, they may experience difficulties in obtaining cooperation from their local partners. 


\section{REFERENCE}

1. Anderson, Erin and Barton Weitz (1992), "The Use of Pledges to Build and Sustain Commitment in Distribution Channels," Journal of Marketing Research, 29 (February), 18-34.

2. Bello, Daniel C. and David I. Gilliland (1997), "The Effect of Output Controls, Process Controls, and Flexibility on Export Channel Performance," Journal of Marketing, 61 (January), 22-38.

3. Brewer, M.B. and R. Kramer (1985), "The Psychology of Intergroup Attitudes and Behavior," In Rosenzweig and Porter (Eds.), Annual Review of Psychology, vol 36, 219-243, Palo Alto, CA: Annual Reviews.

4. Chen, Chao C., Xiao-Ping Chen and James R. Meindl (1998), "How Can Cooperation be Fostered? The Cultural Effects of Individualism-Collectivism," Academy of Management Review, 23(3), 285-304.

5. Chiles, Todd and John McMackin (1996), "Interating Variables Risk preferences, Trust, and Transaction Cost Economics," Academy of Management Review, 21(1), 73-99

6. Churchill, Gilbert A. (1979), "A Paradigm for Developing Better Measures of Marketing Constructs," Journal of Marketing Research, 16 (February), 64-73.

7. Doney, Patricia M. and Joseph P. Cannon (1977), "An Examination of the Nature of Trust in Buyer-Seller Relationships," Journal of Marketing, 61 (April), 35-51.

8. $\quad$ Dore, R (1987), Taking Japan Seriously, Stanford, CA: Stanford University Press.

9. Dyer, Jeffrey and Wujin Chu (2003), "The Role of Trustworthiness in Reducing Transaction Costs and Improving Performance: Empirical Evidence from the United States, Japan, and Korea," Organization Science 14 (1), 57-68.

10. Fijneman, Yvonne, Madde Willemsen and Ype Poortinga (1996), "Individualism-Collectivism," Journal of Cross-Cultural Psychology 27 (4), 381-402

11. Frazier, Gary (1983), Interorganizational Exchange behavior in Marketing Channels: A Broadened Perspective," Journal of Marketing, 47(Fall) 68-78.

12. Ganesan, Shankar, "Determinants of Long-Term Orientation in Buyer-Seller Relationships," Journal of Marketing, 58 (April), 1-19.

13. Geertz, C (1965), "The Impact of the Concepts of Culture on the concept of Man," In New Views on the nature of Man, ed J.R. Platt, University Chicago Press

14. Gooden, Doreen and R. C. Preziosi (2004). Cultural Values and Leadership Behavior In the United States, Jamaica and the Bahamas, International Business and Economics Research Journal, 3(3), 25-34.

15. Griffith, David A, Michael Y Hu and John K Ryans Jr (2000), "Process Standardization across Intra- and Inter- Cultural Relationships," Journal of International Business Studies, 2nd Quarter, 31 (2), 303-25.

16. Gupta, Ashok and David Wilemon (1986), "A Model for Studying R\&D-Marketing Interface in the Product Innovation Process," Journal of Marketing, 50, 7-17.

17. Hagen, James and Soonkyoo Choe (1998), "Trust in Japanese Interrfirm Relations: Institutional Sanctions matter," Academy of management Review, 23 (3), 589-600.

18. Hofstede, Geert (1991), Cultures and Organizations: Software and Mind, London, McGraw-Hill.

19. Hofstede, Geert (1980), "Motivation, Leadership, and Organization: Do American Theories Apply Abroad?," Organizational Dynamics, Summer, 42-63.

20. Kale, Sudhir (1986), "Dealer Perceptions of manufacturer Power and Influence Strategies in a Developing Country," Journal of Marketing Research, 23 (November), 387-393.

21. Kim, U., Triandis, H.C., Kagitcibasi, C., Choi, S-C and G. Yoon (1994), Individualism and Collectivism: Theory, method and applications. Newbury Park, California, Sage.

22. Kirkbridge, P.S., S. Tang and R. Westwood (1991), "Chinese Conflict Preferences and Negotiation Behavior: Cultural and Psychological Influences," Organizational Studies, 12, 365-386.

23. Kumar, Nirmalya, Lisa K. Scheer and Jan-Benedict E. M. Steenkamp (1995), "The Effect of Perceived Interdependence on Dealer Attitudes," Journal of Marketing Research, 32 (August), 348- 356.

24. Kumon, H., Kamiyama, K, H. Itagaki and T Kawamura (1994), "Types of Japanese factories located overseas," Hybrid factory: The Japanese production system in the US, T Abo (Ed) p.181-227, New York: Oxford University Press 
25. Lusch, Robert F. and James R. Brown (1996), "Interdependency, Contracting, and Relational Behavior in Marketing Channels," Journal of Marketing, 60 (October), 19-38.

26. Manna, Dean (2008) Just In Time: Case Studies of Supplier Relationships Across Industries, Journal of Applied Business Research; 24 (1), 75-83.

27. Morgan, Robert and Shelby Hunt (1994), "The Commitment-Trust Theory of Relationship Marketing," Journal of Marketing, 58 (July), 20-38.

28. Moorman, Christine, Gerald Zaltman and Rohit Deshpande (1992), "Relationships Between Providers and Users of Market Research: The Dynamics of Trust Within and Between Organizations," Journal of Marketing Research, 29 (August), 314-328.

29. Noordewier, Thomas G., George John and John R. Nevin (1990), "Performance Outcomes of Purchasing Arrangements in Industrial Buyer-Vendor Relationships," Journal of Marketing, 54 (October), 108-122.

30. Ouchi, William G. (1979), "A Conceptual Framework for the Design of Organizational Control Mechanisms," Management Science, 25 (9), 833- 848.

31. Robicheaux, Robert A. and James E. Coleman (1994), "The Structure of Marketing Channel Relationships," Journal of the Academy of Marketing Science, 22(1), 38-51.

32. Shankarmahesh, Mahesh, John Ford and Michael LaTour (2003), "Cultural Dimensions of Switching Behavior in Importer-Exporter Relationship," 3, 17-33.

33. Schurr, Paul and Julie Ozanne (1985), "influences on Exchange Processes: Buyers' Preconceptions of a Seller's Trustworthiness and Bargaining Toughness," Journal of Consumer Research, 11(March), 939-953.

34. Stern, Louis, Brian Sternthal and Samuel Craig (1973), "Managing Conflict in Distribution Channels: A Laboratory Study," Journal of Marketing Research, 10 (May), 169-179.

35. Triandis, Harry C. (1996), "The Psyuchological Measurement of Cultural Syndromes," American Psychologist, April, 407-415.

36. Triandis, Harry C. (1995), Individualism and Collectivism, Boulder Co; Westview press.

37. Triandis, Harry C., C. McCusker and C.H. Hui (1990), "Multimethod Probes of Individualism and Collectivism. Journal of Personality and Social Psychology 59, 1006-1020.

38. Triandis, Harry C., Robert Bontempo, Marcelo J. Villareal, Masaaki Asai and Nydia Lucca (1988), "Individualism and Collectivism: Cross-Cultural Perspectives on Self-Ingroup Relationships," Journal of Personality and Social Psychology, 54 (2) 323-338.

39. Wagner III, John A. (1995), "Studies of individualism-Collectivism: Effects on Cooperation in Groups," Academy of Management Journal, 38(1), 152-172.

40. Williams, Jerome D., Sang-Lin Han and William J. Qualls (1988), “A Conceptual Model and Study of Cross-Cultural Business Relationships," Journal of Business Research, 42, 135-143.

41. Williamson, Oliver (1985), The Economic Institutions of Capitalism, New York: Free Press

42. Wong, Alfred, Dean Tjosvold, Winnie Y.L. Wong and C. Liu (1999), "Cooperative and Competitive Conflict for Quality Supply Partnerships between China and Hong Kong," International journal of Physical Distribution and Logistics 29(1), 7-21. 